\title{
Right atrial volume and body mass index in corrected tetralogy of Fallot correlate with the incidence of supraventricular arrhythmia - an MRI study
}

\author{
Michael Steinmetz ${ }^{1 *}$, Jan M Sohns ${ }^{2}$, Christina Schulte ${ }^{2}$, Christoph H Preuss $^{1}$, Antonia Zapf ${ }^{4}$, Wieland Staab², \\ Johannes T Kowallick ${ }^{2}$, Christina Unterberg-Buchwald ${ }^{3,2}$, Thomas Paul ${ }^{1}$, Joachim Lotz ${ }^{2}$
}

From 16th Annual SCMR Scientific Sessions

San Francisco, CA, USA. 31 January - 3 February 2013

\section{Background}

Patients with corrected Tetralogy of Fallot (cTOF) can develop supraventricular arrhythmias. So far, right atrial (RA) volume in TOF has not been evaluated in the context of arrhythmia. The aim of this study was to evaluate if right atrial (RA) volume in TOF correlates with the occurrence of supraventricular arrhythmias. To identify other risk factors for arrhythmias additional parameters were included in the analysis: anthropomorphic parameters (BMI, age, gender), previous shunt, high right ventricular $(\mathrm{RV})$ volumes and pulmonary regurgitation (PR).

\section{Methods}

Cardiac MRI (CMR) and 24h Holter ECG-monitoring were performed in 69 consecutive patients with cTOF (Table 1). CMR protocol included triplanar HASTE sequences, standard SSFP cine images, flow measurements of the aorta, pulmonary trunk and pulmonary arteries. RA and LA volumes were retrieved from HASTE sequences and SSFP cine images.

\section{Results}

Mean values for RA volume were $49+-19 \mathrm{ml} / \mathrm{m}^{2}$ from HASTE sequences. In 23 patients endsystolic and enddiastolic RA-volumes were obtained from cineSSFP and compared to HASTE sequences. Bland-Altman analysis confirmed correlation of RA volumes from both sequences in atrial diastole with minimal overestimation by HASTE

'Pediatric Cardiology and Intensive Care Medicine, University Medical Center Goettingen, Goettingen, Germany

Full list of author information is available at the end of the article
Table 1 Patient cohort characteristics

\begin{tabular}{ccc}
\hline & Number of patients & Mean \\
\hline $\mathrm{n}$ & 69 & \\
\hline Female & 35 & \\
\hline Male & 34 & \\
\hline Age & $11-54$ & 31 years \\
\hline BMl & $15.5-36.1$ & $25 \mathrm{~kg} / \mathrm{m}^{2}$ \\
\hline shunt & 37 & \\
\hline Transanular patch plasty & 47 & \\
\hline pulmonary vavle comissurotomy & 13 & \\
\hline Pulmonary conduit/ homograft & 41 & \\
\hline
\end{tabular}

sequences. Mean RV volumes were $97+-27 \mathrm{ml} / \mathrm{m}^{2}$, pulmonary valve regurgitation fraction $21+-19 \%$. Mean heart rate on Holter was 75, ranging from from 52 to 124 bpm. 57 of 69 patients had supraventricular arrhythmias as singular extrasystolies, couplets or short runs. Mean BMI was $25 \mathrm{~kg} / \mathrm{m}^{2}$ with a range from 15.5 to $36 \mathrm{~kg} / \mathrm{m}^{2}$.

Based on multivariate regression analysis RA volume $(\mathrm{p}<0.01)$ as well as BMI $(\mathrm{p}<0.01)$ were identified as independent risk factors for supraventricular arrhythmias. No correlation was found for gender, age, previous shunt, RV volume or degree of residual pulmonary regurgitation.

\section{Conclusions}

TOF patients with high RA volumes or high BMI exhibited supraventricular arrhythmias more often, regardless of age, gender, previous shunt, RV volume or PR. 


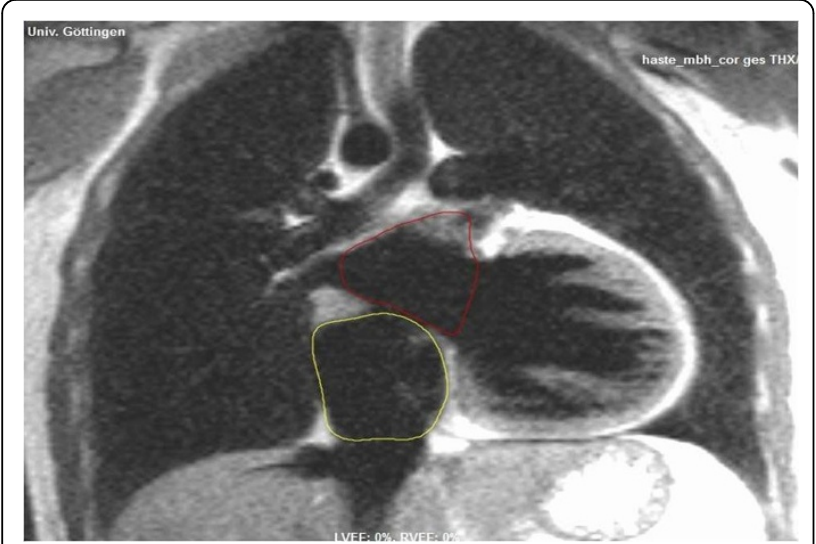

Figure 1 Example of right atrial segmentation on coronal HASTE.

\section{Funding}

None.

\section{Author details}

${ }^{1}$ Pediatric Cardiology and Intensive Care Medicine, University Medical Center Goettingen, Goettingen, Germany. ${ }^{2}$ Diagnostic and Interventional Radiology, University Medical Center Goettingen, Goettingen, Germany. ${ }^{3}$ Cardiology and Pulmonology, University Medical Center Goettingen, Goettingen, Germany. ${ }^{4}$ Medical Statistics, University Medical Center Goettingen, Goettingen, Germany.

Published: 30 January 2013

doi:10.1186/1532-429X-15-S1-E91

Cite this article as: Steinmetz et al:: Right atrial volume and body mass index in corrected tetralogy of Fallot correlate with the incidence of supraventricular arrhythmia - an MRI study. Journal of Cardiovascular Magnetic Resonance 2013 15(Suppl 1):E91.

\section{Submit your next manuscript to BioMed Central} and take full advantage of:

- Convenient online submission

- Thorough peer review

- No space constraints or color figure charges

- Immediate publication on acceptance

- Inclusion in PubMed, CAS, Scopus and Google Scholar

- Research which is freely available for redistribution

Submit your manuscript at www.biomedcentral.com/submit
C Biomed Central 